ESCRITAS Vol. 11 n. 1 (2019) ISSN 2238-7188 p.33-51

\title{
AS JOIAS TRADICIONAIS EM FILIGRANA NAS FESTAS RELIGIOSAS DE NATIVIDADE, TOCANTINS
}

\section{THE TRADITIONAL JEWELS IN FILIGRANA IN THE RELIGIOUS NATIVITY FESTIVALS, TOCANTINS}

\author{
Rosane Balsan ${ }^{1}$ \\ Wátila Misla Fernandes Bonfim²
}

\section{RESUMO}

O ofício da ourivesaria e a arte dos mestres filigraneiros, aponta Iphan (2007), não pode ser visto desatrelado de outras manifestações religiosas nativitanas, como a celebração do Divino Espírito Santo, a festa da padroeira Nossa Senhora da Natividade e a festa do Nosso Senhor do Bonfim, bem como da confecção de bolos e biscoitos de D. Naninha. Está tudo entrelaçado: as festas, as práticas, personagens e saberes que identificam a cultura imaterial de Natividade. Desse modo, o presente artigo busca demostrar a relação das joias artesanais que marcam o espaço e lugar nativitano e as festas religiosas seculares e presentes no dia a dia e no imaginário local.

PALAVRAS-CHAVE: Natividade, Joias artesanais, Festas religiosas, Lugar.

\begin{abstract}
The craft of goldsmithing and the art of filigree masters, according to Iphan (2007), cannot be seen in disarray of other nativist religious manifestations, such as the celebration of the Divine Holy Spirit, the feast of the patroness of Our Lady of the Nativity and the feast of Our Lord of the Nativity Bonfim, as well as the baking and biscuits of D. Naninha. Is all intertwined: the parties, practices, characters and knowledge that identify the immaterial culture of Natividade. In this way, the present article seeks to demonstrate the relation of the handmade jewels that mark the space and nativitano place and the religious celebrations secular and present in the day to day and in the local imaginary.
\end{abstract}

KEYWORDS: Nativity, Handmade Jewelry, Religious Festivals, Place.

\footnotetext{
${ }^{1}$ Professora associada II da Universidade Federal do Tocantins (UFT), Campus de Porto Nacional. Mestrado em Geografia pela Universidade Estadual Paulista Júlio de Mesquita Filho (2001) e doutorado em Geografia pela Universidade Estadual Paulista Júlio de Mesquita Filho (2005).

${ }^{2}$ Mestranda em Geografia pela Universidade Federal do Tocantins (2017). Professora da Educação Básica da Secretaria da Educação e Cultura. Assessora do currículo de História da Secretaria Municipal de Educação de Dianópolis. Graduada em História pela Universidade Federal do Tocantins (2006).
} 


\section{INTRODUÇÃO}

A cidade de Natividade, tombada pelo IPHAN em 1987, e considerada a localidade mais antiga do Tocantins, teve seu princípio marcado pela busca de ouro e pela escravidão. Segundo fontes orais a presença de ourives na cidade remonta ao século XVIII. Uma das representações imateriais da cidade são as joias artesanais e/ou filigranadas, uma tradição de mais de um século e ainda presente, sobretudo nos dias de festas religiosas.

Inicialmente, Natividade foi Batizada de Arraial de São Luís, uma homenagem ao então Governador de São Paulo, D. Luís de Mascarenhas, que em 1740 veio pessoalmente às ricas minas recém descobertas, visto serem elas alvo de disputas pelas Capitanias do Maranhão e do Pará. Ali estando, D. Luís comandou o alinhamento das primeiras ruas, tortuosas e estreitas (PALACÍN, 1987). Porém, para Vaz (1985), Natividade tem três hipóteses para sua fundação: o arraial teve suas origens no arraial de São Luiz, localizado no alto da serra; as ruínas de São Luiz teriam acomodado apenas os garimpeiros e escravos, enquanto o núcleo original teria surgido nas encostas da elevação; ou Natividade teria convivido ao mesmo tempo com o arraial de São Luiz (Ainda hoje há ruínas, como: alicerces de antigas construções, lago artificial, pontes, aquedutos localizados no alto da serra).

No entanto, a versão mais aceita é a de que nos primeiros tempos o sítio urbano se localizava no alto da serra, hoje denominado "ruínas de São Luiz". Há, ainda, vestígios em pedra das primeiras habitações bem como desvios d'água feitos pelos escravos com o propósito de facilitar o trabalho prospector.

Em Natividade, de acordo com o Iphan (2007), o tempo presente é expressivamente influenciado pelo passado do século XVIII, além da origem, as ruínas do início da cidade localizadas na serra, ventilam o sentido da coletividade das pessoas, ou seja, o reluzente metal aurífero faz parte do imaginário presente, criando expectativas nos citadinos.

Esta pesquisa foi realizada através da abordagem qualitativa. Para Mendes e Silva (2013), tornou-se crescente a complexidade dos arranjos sociais, tornando-se difícil entender e explicar os fatores econômicos, políticos e socioculturais apenas com a utilização da pesquisa quantitativa. Desse modo, a abordagem qualitativa baseia-se em compreender e interpretar os fenômenos a partir de suas representações, crenças, 
opiniões, percepções, atitudes e valores. Nela, o pesquisador interage dinamicamente com o sujeito pesquisado, numa relação de interdependência. Além disso, esclarecemos que para a operacionalização da investigação utilizou-se as seguintes siglas: $M$ (Moradores); O (Ourives); EO (Ex-Ourives), AP (Aprendizes).

\section{FILIGRANA - UMA ARTE MILENAR}

A filigrana é uma arte de trabalhar metais, é essencialmente uma técnica de ourivesaria, do tipo popular. Esta arte não é específica da tradição portuguesa, “[...] pois existe noutros países e culturas, porém é uma das formas mais típicas das artes portuguesas. A filigrana (Figura 2), ao longo do tempo tem sido acompanhada por duas correntes, no que diz respeito à sua produção e ao seu uso" Marques (2014, p. 43). Inicialmente, a técnica da filigrana foi considerada um artefato secundário da joia, aplicada em adereços de luxo, de uso profano e sagrado, com detalhes dos desenhos, fazendo desta arte imaginária, um tipo de ourivesaria dirigida às classes com mais posses (MARQUES, 2014).

Figura 1. Arrecadas em filigrana, influência fenícia na ourivesaria.

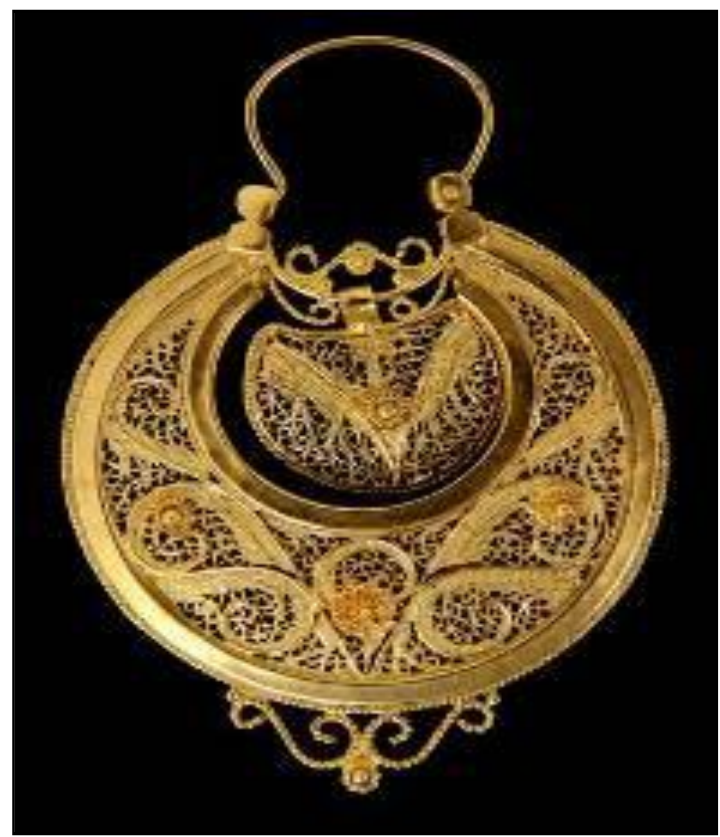

Fonte: PEREIRA (2008, p. 18).

Para Guarnieri e Ribeiro (2012), por se tratar de ensino e aprendizado passados através do convívio entre povos desde cerca de 2.500 anos a.C., a filigrana agregou influências de todos, os que transmitiam e os que a acolhiam, de geração em geração. Tal circunstância corrobora as características que marcam a história da filigrana e 
permite encontrar os rastros de seu desenvolvimento durante os séculos de existência do gênero humano.

Portugal, argumenta Pereira (2008, p. 15), “[...] desde a época em que estava inserido no vasto império romano, possuía explorações auríferas em seu território, sobretudo na região Noroeste: ouro, prata, cobre, ferro eram abundantes". A riqueza em ouro que brotava das minas do Noroeste era significativa, vestígios resultantes das escavações de antigas minas do ouro encontrados em Vila Pouca de Aguiar e na região do Douro corroboram essa prerrogativa: Valongo, Paredes, Gondomar, Castelo de Paiva, Penedono, Trás-os-Montes, Mirandela, Chaves; além do Alto Minho, como a Serra de Arga, entre outras localidades, todas com localização na parte Norte. (PEREIRA, 2008).

Em terras nativitanas, logo depois das descobertas das primeiras lavras em 1734, o ouro era extraído utilizando-se a mão de obra escravizada africana nos veios dos córregos da região de forma aluvional. Atualmente, o ouro que abastece as ourivesarias dando incremento às atividades dos artesãos filigraneiros é extraída em "caixas", que chegam ao subsolo, com até 130 metros de profundidade. Destacando-se hoje os garimpos do Príncipe, pequeno povoado de Natividade. O ouro e a prata são levados à superfície, onde as pedras são moídas, lavadas e processadas até terem a aparência dos cobiçados metais. Sobre a época preferida para usarem as suas joias filigranadas, as nativitanas comentaram:

M1 - Eu uso o ano inteiro, mais nas festas religiosas do Divino e da padroeira.

M3- Eu não tiro essas joias nem para dormir.

M7 - Algumas joias em festas da padroeira, outras no dia a dia, no domingo.

M9 - Nas festas tradicionais religiosas padroeira e festa do Divino, Romaria do Senhor do Bonfim.

M10 - Uso mais no festejo do Divino Espírito Santo.

M13 - O hábito é antigo, minha avó tinha muito ouro, muitas joias, a própria igreja incentivava as pessoas se embelezarem para as festas.

Constata-se a existência de conjuntos expressivos de manifestações culturais em Natividade, assim como Ferreira (2005) percebeu em cidades antigas da região do vale do Paraíba, localidades que tem suas origens na época da Colônia e que hoje resistem de diferentes formas à homogeneização imposta pelo projeto neoliberal.

Os rituais e costumes do passado não são somente soluções úteis ou meras expressões conservadoras. Seu sentido vai mais longe e se mostra mais nítido quando se descobre neles formas de resistir aos efeitos de formadores da cultura dominante. Nestas manifestações se encontram soluções para o presente. Não se trata de conservadorismo, mas, em muitos casos, de 
preservação de uma base, a partir da qual resiste, conservando a identidade, a dignidade e solidariedade (FERREIRA, 2005, p. 62).

Percebe-se, no que diz respeito à Natividade, a forte relação com a memória histórica, que se materializa nas suas festas religiosas, e permanecem ativas, mesmo tendo que concorrer com shows e festas modernas. Desse modo, as festas religiosas, assim como a técnica da filigrana, que vem sendo mantidas há pelo menos um século, representam uma forma de resistência cultural, frente à proposta neoliberal de homogeneização das ideias, dos hábitos, dos adereços e dos mercados.

Cada festa comporta uma organização comunitária e uma regulamentação da parte do grupo festivo, que é mais ou menos amplo ou complexo. Neste componente organizacional, ao lado do elemento organizativo-comunitário entra o quadro de referência ideológico anteposto à festa e que, segundo o caso, se refere a um mito de origem ritual ou simbolicamente reatualizado, à lenda de fundamentação de um culto, à imagem de um santo cristão, a um momento crítico da existência ou a um evento histórico, social ou político, que deve ser comemorado e re-evocado, para renovar o impulso de vencer os percalços da cotidianidade através do fenômeno festivo (FERREIRA, 2005, p. 71).

Esclarece Ferreira (2005), que durante os rituais festivos é possível extrair os elementos de identidade mais significativos de uma determinada cultura, bem como entender estes elementos como um sistema de comunicação, "que permite ao observador avaliar como o passado e o presente se articulam no interior desta cultura e as várias formas de identidade que são ao mesmo tempo ressignificadas, assumindo novos aspectos" (FERREIRA, 2005, p. 72).

As festas são desse modo, importantes instrumentos de significação entre os homens e a precariedade da vida, onde os seres humanos buscam respostas para as aflições e agruras do cotidiano.

No que tange ao uso das joias pelas moradoras de Natividade, os ourives e exourives entrevistados responderam que as nativitanas têm preferência em comprar e utilizar os adereços principalmente durante a festa do Divino Espírito Santo, seguida da festa de Nossa Senhora da Natividade. Outras datas/épocas do ano também foram citadas em menor quantidade: romaria do Bonfim, natal e carnaval (Quadro 1).

Quadro 1. Uso das joias tradicionais em festas ou outras épocas do ano em Natividade

\begin{tabular}{|l|c|c|c|}
\hline $\begin{array}{c}\text { Ourives/ ex-ourives } \\
\text { e aprendizes }\end{array}$ & $\begin{array}{c}\text { Festa do Divino } \\
\text { Espírito Santo }\end{array}$ & $\begin{array}{c}\text { Festa de Nossa } \\
\text { Senhora da } \\
\text { Natividade }\end{array}$ & $\begin{array}{c}\text { Outra festa ou época } \\
\text { do ano (Bonfim, Natal, } \\
\text { Carnaval etc) }\end{array}$ \\
\hline O1 & $\mathrm{X}$ & $\mathrm{X}$ & \\
\hline $\mathrm{O} 2$ & $\mathrm{X}$ & $\mathrm{X}$ & $\mathrm{X}$ \\
\hline $\mathrm{O3}$ & $\mathrm{X}$ & $\mathrm{X}$ & $\mathrm{X}$ \\
\hline $\mathrm{O4}$ & $\mathrm{X}$ & & \\
\hline
\end{tabular}




\begin{tabular}{|l|c|c|c|}
\hline O5 & $X$ & $X$ & $X$ \\
\hline O6 & $X$ & $X$ & \\
\hline O7 & $X$ & $X$ & \\
\hline O8 & $X$ & $X$ & \\
\hline O9 & $X$ & & \\
\hline O10 & $X$ & $X$ & \\
\hline EO1 & $X$ & $X$ & \\
\hline EO2 & $X$ & & $X$ \\
\hline EO3 & $X$ & & \\
\hline AP1 & $X$ & $X$ & \\
\hline AP2 & $X$ & $X 8$ & \\
\hline
\end{tabular}

Fonte: Dados coletados da pesquisa, 2017.

Em relação ao uso das joias tradicionais mencionadas pelos ourives, ex-ourives e aprendizes das ourivesarias nativitanas, percebeu-se que $100 \%$ deles apontou que as moradoras tem a festa do Divino Espírito Santo como referência para a utilização dos adornos; enquanto $66 \%$ dos entrevistados citaram o uso dos adereços nativitanos na festa da padroeira Nossa Senhora da Natividade. As outras festas e/ou épocas: festa de Nosso Senhor do Bonfim, o carnaval, e o natal, foram citadas por $33 \%$ dos entrevistados.

Antes da invenção dos modernos meios de comunicação, enfoca Ferreira (2005), as festas constituíam importantes veículos de comunicação e interatividade pública: eram momentos de afirmação da identidade coletiva, a vida e o lugar se mostravam nas festas, lugares simbólicos através dos quais o indivíduo tomava consciência de seu "pertencimento" a determinado grupo.

Em Natividade, pertencer a um grupo, igreja ou irmandade transcende o instante presente, sendo um legado colonial. Pertencer a uma igreja ou irmandade representava muito mais do que a simples presença nas festas, mas alívio eterno.

Ensina Karash (2012), que em Natividade existiu por volta do final do século XVIII, a Irmandade de Nossa Senhora do Rosário dos Pretos, onde os negros professavam sua religiosidade sob a roupagem do catolicismo, tinham um espaço para se reunirem, socializarem as dificuldades do dia a dia, e se organizarem em festas.

No ano de 1786, a irmandade de Nossa Senhora do Rosário construía uma igreja em Natividade que seria a maior igreja do Brasil central. Segundo uma tradição local, os escravos não terminaram a igreja por causa da abolição da escravatura, mas outra tradição oral reza que foi o declínio da mineração do ouro no fim do período colonial que não permitiu aos escravos angariar recursos para finalizar a obra. Esses escombros de uma igreja grande indicam a existência de uma forte comunidade de católicos praticantes, mas pouco sabemos deles ou de suas crenças no final do Brasil Colônia (KARASCH, 2012, p. 54). 
Participavam dessa irmandade escravos e forros, que utilizavam os seus adereços, como as joias. Pela quantidade de ouro que doavam é possível deduzir a utilização desses objetos.

Para aqueles que viveram no fim do período colonial, os serviços mais valiosos das irmandades dos pretos eram para louvar Nossa Senhora, honrar os santos negros e consolar os irmãos com os ritos religiosos fundamentais, sobretudo orações pela alma dos mortos. Pode-se comprovar que os negros valorizavam esses ritos pela quantidade significativa de ouro que eles doavam às irmandades dos pretos para a compra de cera para velas e pelo pagamento de missas, funerais e orações pelos seus mortos. As festas mais importantes que os membros financiavam eram as procissões e as missas solenes, com música nos dias de Nossa Senhora do Rosário e de São Benedito (KARASCH, 2012, p. 55).

A festa reproduz simbolicamente a condição do caos mítico primordial, quando promove a anulação do presente. “[...] Assim, a festa é um simbólico retorno às origens - uma origem muitas vezes imaginária ou reinterpretada - necessário para garantir a integridade do indivíduo" (FERREIRA, 2005, p. 75).

Os rituais festivos, aponta Ferreira (2005), possuem uma dupla e contraditória potencialização entre conservação e criatividade cultural. De um lado, levam o indivíduo à fuga, à evasão da realidade banal, do cotidiano, para imergir no momento mágico da festa, que é também o momento do sagrado. De outro lado, evidencia Ferreira (2005, p. 75) que “[...] o clima festivo abre possibilidade psicológica e fornece uma carga de energia psíquica que permite ao indivíduo enfrentar com vigor e independência criativa as batalhas do cotidiano". Em Natividade, a Festa do Divino Espírito Santo e a Festa de Nossa Senhora da Natividade são apenas alguns exemplos de festas que carregam a tradição cristã-europeia com algumas adaptações de origem africana.

Tanto na festa do Divino, quanto na da padroeira Natividade, enfoca Iphan (2007), quase não são ostentadas joias produzidas em outros lugares: nos colos, nas mãos, orelhas e punhos, descortinam-se Corações Nativos, as pombinhas do Divino, o Globo, a pulseira Escrava, Flores de Maracujá, a Peixa etc. No que diz respeito à relação entre as joias e as festas religiosas, como Divino Espírito Santo e de Nossa Senhora da Natividade, obteve-se as seguintes declarações das depoentes:

M3 - Acho que tem relação, a pomba, o Coração, a Peixa.

M5 - Acho que sim, as joias são daqui, as festas também são daqui.

M6 - As festas influenciam o uso das joias, cada pessoa quer se apresentar mais bonita.

M9 - Porque as joias tradicionais tem símbolo religioso, como o peixe e a Pomba, o brinco Cacho de Uva, crucifixo.

M11 - Acho que sim, pelo fato da valorização da religião e das joias. 
M12 - O hábito de usar joias nas festividades sempre existiu, porém com a ourivesaria Mestre Juvenal o uso da prata aumentou... geralmente as pessoas usam mais joias, o Divino, o Coração Nativo.

M14 - O elo entre as festas e as joias é a tradição.

M16 - É uma ligação mais pela tradição, elas não guardam as joias nessas datas, fazem questão de usar.

Com relação as principais festas religiosas da cidade, escolheu-se a Festa do Divino Espírito Santo e a festa de Nossa Senhora da Natividade, ambas de presença secular e que marcam o cotidiano e a organização do espaço nativitano.

\section{FESTA DO DIVINO ESPÍRITO SANTO}

Em Natividade, a grande festa religiosa esperada pela população é a do Divino Espírito Santo. Nesse momento, mais do que em qualquer outro, emerge a utilização de joias tradicionais confeccionadas tanto em ouro como em prata pelos artesãos filigraneiros locais: brincos, corações, pulseiras, anéis, crucifixos colares; como a "Pombinha do Divino", a "Peixa", brinco Flor de Maracujá, o Coração Nativo, anel Escravo podem ser vistos nas pessoas ${ }^{3}$.

No que tange ao Divino, sabidamente uma das peças mais antigas e tradicionais, atualmente são 4 tipos feitos em Natividade, é confeccionada utilizando-se a técnica da filigrana. A celebração do Divino Espírito Santo (Figura 2), é a festa de maior expressividade, e conta com a participação de grande parte da população. O festejo do Divino Espírito Santo é uma celebração com data móvel, estipulada pela data da Páscoa. A sua origem não se sabe ao certo, mas sua institucionalização, nos inícios do século XIV, é atribuída à rainha Isabel e ao rei Dinis, rei de Portugal (IPHAN, 2007).

Figura 2. Festa do Divino Espírito Santo, Natividade, Tocantins.

\footnotetext{
${ }^{3}$ Constatação realizada in locu na festa do Divino Espírito Santo no ano de 2017 e 2018.
} 


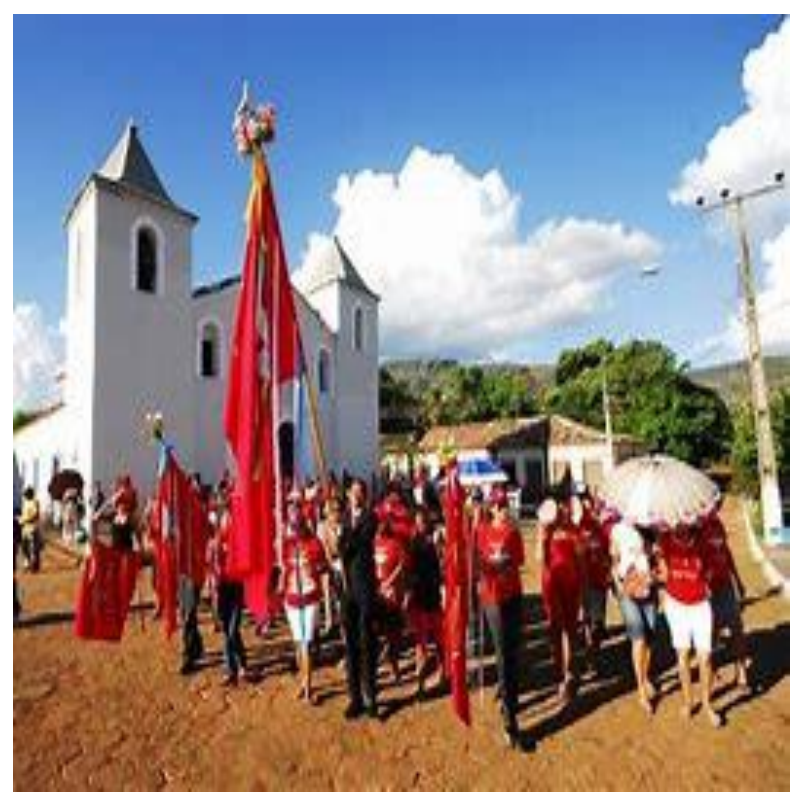

Fonte: ASCCUNA.

a festa de Pentecostes com os paramentos vermelhos, símbolos e sinal do amor com que Deus ama os homens e do fogo que aquece, ilumina e abrasa os corações dos discípulos de Jesus. A Pomba é o grande símbolo do Divino (IPHAN, 2007).

Destaca o Iphan (2007), que no Brasil a festa do Divino Espírito Santo teria chegado com a colonização e se firmado em meados do século XVII. Essa manifestação que ocorre em diversas regiões do país, na América portuguesa, estaria intimamente ligada ao período da mineração de ouro e se conservado especialmente nas grandes cidades goianas do século XVIII, e Natividade está neste contexto.

Ainda hoje, nesta localidade, a celebração do Divino se caracteriza pela repercussão que tem entre o povo, mobilizando-o para participar dos eventos ou a ele assistir. Por grande parte das cidades que foram formadas no contexto da mineração, há uma grande festa que comemora o Divino ${ }^{4}$.

As Folias do Divino anunciam a presença do Espírito Santo e conduzem a bandeira do Divino. O giro da Bandeira representa as andanças de Jesus Cristo e seus doze apóstolos durante os quarenta dias, levando luz e sua mensagem, convidando a todos para a festa da hóstia consagrada. Os foliões representam os apóstolos e são conduzidos pelo alferes em sua jornada pela zona rural. Este grupo percorre a zona rural, abençoando as famílias e unindo-as em torno da celebração da festa que se aproxima. Saem a cavalo ou a pé pelas trilhas ou estradas e, quando chegam ao local do pouso, alinham-se no terreiro e cantam a licença, pedindo ritualmente acolhida (IPHAN, 2007, p. 3).

\footnotetext{
${ }^{4}$ Durante as festas do Divino Espírito Santo a cidade de Natividade recebe visitantes do Tocantins inteiro, de outros estados e até do exterior.
} 
Os encontros das festas se configuram em momentos de festividade, quando os cidadãos nativitanos também aproveitam para se divertir e confraternizar. A festa do Divino envolve a comunidade como um todo e a ourivesaria em filigrana está presente principalmente por meio do uso das peças relacionadas à festividade, o que se evidencia na figura da pombinha estampada em brincos, pingentes e anéis. A comemoração das festividades do Divino na cidade de Natividade é de cunho popular, aponta Iphan (2007, p. 4) "[...] e une e integra aspectos sagrados aos profanos. A festa é comemorada com longos períodos de oração e cantos de louvor, mas se mistura com cantos e danças realizadas em profunda alegria".

A população nativitana demonstra grande fé no Divino e foi possível perceber que essa fé transcende os dias da festa, ela se expressa em seu cotidiano à medida que está presente das mais variadas formas nas casas e na vida das pessoas. Bandeiras do Divino podem ser encontradas em muitas casas, bem como em cartazes e camisetas, em suas orelhas, dedos, pescoços; pode-se ver o Divino representado pelas joias confeccionadas pelos ourives locais (Iphan, 2007, p. 4).

A comunidade Nativitana, de um modo geral, se envolve em todas as etapas da preparação da festa. Durante o período festivo, o tempo cotidiano é substituído pelo tempo ritual da festa - é a ruptura da rotina. A comunidade "se purga" de suas contradições sociais - o espaço da festa passa a ser território comum em que todos os cidadãos circulam/convivem para além de suas diferenças. E, por vezes, evidenciandoas, principalmente pelo uso das tradicionais joias nativitanas.

Afinal as festividades não são estruturas fixas, mas um contínuo de mudanças: as celebrações pouco se transformam, e ao mesmo tempo escapam ao desgaste do tempo. São sempre as mesmas, mas nunca iguais. Nelas estão inseridos os folguedos - Catira, a roda e a sússia, Folias ou - representações que se dão por vezes em cortejo, tendo por cenários as ruas e praças tombadas do centro histórico da cidade, especialmente nos dias de festas em louvor do Divino, da padroeira e do calendário litúrgico ou profano (IPHAN, 2007, p. 4).

Durante toda a festividade do Divino é possível perceber a relação historicamente construída entre esta festividade e a cultura aurífera local, principalmente pelo uso de joias das ourivesarias locais, muitas vezes confeccionadas especialmente para estas festividades. Nesse momento, a festa e a joia representam para o nativitano o seu lugar. A festa do Divino Espírito Santo reúne todos os anos grande quantidade de moradores, nativitanos que residem em outras cidades e turistas do Tocantins e de outros estados brasileiros. Averiguou-se de acordo com os moradores entrevistados que as joias mais utilizadas são: brinco Flor de Maracujá, Coração Nativo, pingente Pomba do Divino. Logo em seguida temos: colar Flor de Maracujá, Coração 
Português. Outras joias citadas foram: crucifixo, anel Escravo, pulseira Flor de Maracujá, colar Lantejoula, anel do Divino, colar de Contas. Foi citado uma única vez: Sete Vidas e a Flor Maria da Penha (Quadro 2).

Quadro 2. Joias mais citadas pelos moradores entrevistados em Natividade

\begin{tabular}{|c|c|}
\hline Joias nativitanas & Joias utilizadas na festa do Divino Espírito Santo \\
\hline Pingente Pomba do Divino & 8 \\
\hline Peixa & 5 \\
\hline Anel Escravo & 2 \\
\hline Sete Vidas & 1 \\
\hline Crucifixo & 3 \\
\hline Colar Flor de Maracujá & 4 \\
\hline Brinco Flor de Maracujá & 11 \\
\hline Coração Nativo & 12 \\
\hline Pulseira Escrava & 1 \\
\hline Pulseira Flor de Maracujá & 2 \\
\hline Flor Maria da Penha & 1 \\
\hline Colar de Lantejoula & 4 \\
\hline Coração Português & 4 \\
\hline Colar de Contas & 2 \\
\hline Anel do Divino & 2 \\
\hline
\end{tabular}

Fonte: Dados coletados da pesquisa, 2018.

A festa do Divino Espírito Santo é considerada pela população a principal festa realizada na cidade, nessa ocasião as peças tradicionais e filigranadas marcam a religiosidade e a identidade local.

O uso das joias nessas festividades atribui sentido simbólico, econômico e religioso às peças, conforme Iphan $(2007$, p. 5) “[...] é possível encontrá-las em pessoas de todos os segmentos sociais, o metal que, fundido, se transformou em pombas, corações, figas, flores de maracujá e fios, que ornam pescoços, braços e cinturas”.

O povo, sobretudo os devotos, vem às festividades bem vestidos e com muitas joias artesanais em ouro e prata os adornando. Importante salientar que no que tange ao material utilizado, as joias em ouro e em prata praticamente se equivalem, com pequena vantagem para as confeccionadas em ouro.

As joias foram confeccionadas pelos ourives locais, evidenciando como os fios de ouro e prata da filigrana se entrelaçam com os fios da vida dos nativitanos. As joias em filigrana são usadas como forma de ostentação do poder econômico, mas principalmente pelo poder religioso e simbólico que as peças possuem. A grande maioria das peças tradicionais ligadas à religiosidade é verdadeiramente artística; entre elas podemos encontrar principalmente: a pomba do Divino em formato de anel, brinco, broche, pingente, crucifixos variados, peixes articulados (peixa), brincos cacho de uva, corações de filigrana, colares em conta e lantejoula, entre outros (IPHAN, 2007, p. 10). 
Sobre a Festa de Nossa Senhora da Natividade, de acordo com o viajante austríaco Pohl, provavelmente tenha sido a primeira festa a ser comemorada em Natividade, posto que a imagem da santa Nossa Senhora da Natividade data de 1735, e a igreja de Nossa Senhora da Natividade de 1759 (IPHAN, 2007). Portanto, essa festa teria surgido ainda nos tempos áureos da mineração de ouro na região.

Em 1819, o viajante, naturalista e botânico austríaco Johann Emanuel Pohl, esteve em Natividade:

\begin{abstract}
Precisamente ao tempo de nossa estada, aqui se realizaram as novenas da Natividade da Virgem Maria. A igreja da Natividade de Nossa Senhora estava inteiramente iluminada à noite, quando os sacerdotes celebravam as vésperas. Aqui também são usadas, em vez de lâmpadas, cascas de laranja cheias de óleo de rícino. Eram colocadas em suportes feitos de talos leves de buritizeiro, e, distribuídas em toda a altura e largura da igreja, viam-se as letras V.S.D.N. (Viva a Senhora da Natividade). Essa iluminação é custeada pelos juízes e juízas eleitos pelo povo. O juiz deve fornecer a pólvora, os tiros de regozijo e a aguardente necessária, e pagar os músicos. A juíza fornece o óleo para a iluminação da igreja, bem como as frutas conservadas em açúcar (POHL, 1976, p. 272).
\end{abstract}

Segundo Pohl (1976), a festa teve seu ápice no dia 8 de setembro, data em que os moradores apareceram em trajes de gala, e por motivo da igreja destinada à liturgia se encontrar em ruínas, comemorou-se a festividade na igreja de São Benedito. Havia sacerdotes e alguns milicianos fardados. No final foram disparados tiros e foguetes. À tarde encerrou-se a festa com uma procissão em que apareciam muitas bandeiras, além de músicos, rabequistas e cantores. Percebeu-se, porém, a ausência de senhoras na procissão.

O hábito de se ornar para as festas é algo antigo e secular em Natividade. $\mathrm{Na}$ festa da padroeira Nossa Senhora da Natividade, que acontece no mínimo a duzentos anos, descobriu-se, ao indagar moradores da cidade que as joias mais utilizadas são: brinco Flor de Maracujá, Coração Nativo, pingente Pomba do Divino e a Peixa. Seguidas de: crucifixo, colar Flor de Maracujá e colar de Lantejoula. Outras joias citadas foram: anel Escravo, anel do Divino, pulseira Escrava, pulseira Flor de Maracujá e Coração Português ${ }^{5}$. Foi citada uma única vez: colar de Contas e Flor Maria da Penha (Quadro 3).

\footnotetext{
${ }^{5}$ Constatação realizada in locus na festa de Nossa Senhora da Natividade de 2017.
} 
Quadro 3. Joias mais citadas pelos moradores entrevistados em Natividade

\begin{tabular}{|c|c|}
\hline Joias nativitanas & $\begin{array}{c}\text { Joias utilizadas na festa de Nossa Senhora da } \\
\text { Natividade }\end{array}$ \\
\hline Pingente Pomba do Divino & 8 \\
\hline Peixa & 6 \\
\hline Anel Escravo & 2 \\
\hline Anel do Divino & 2 \\
\hline Crucifixo & 4 \\
\hline Colar Flor de Maracujá & 3 \\
\hline Brinco Flor de Maracujá & 11 \\
\hline Coração Nativo & 12 \\
\hline Pulseira Escrava & 2 \\
\hline Pulseira Flor de Maracujá & 2 \\
\hline Flor Maria da Penha & 1 \\
\hline Colar de Lantejoula & 4 \\
\hline Coração Português & 3 \\
\hline Colar de Contas & 1 \\
\hline
\end{tabular}

Fonte: Dados coletados da pesquisa, 2017.

$\mathrm{Na}$ festa de Nossa Senhora da Natividade (Figura 3), que talvez seja a de existência mais antiga, posto que segundo a tradição oral a imagem da santa exposta no altar da igreja data de 1735 , as joias mais utilizadas também coincidem com as mais usadas na festa de Divino: brinco flor de Maracujá, Coração Nativo, pingente Pomba do Divino, Peixa. Também se destacam o colar de Lantejoula, colar Flor de Maracujá, crucifixo.

Figura 3. Festa de Nossa Senhora da Natividade e Mulher nativitana usando joia em filigrana. 


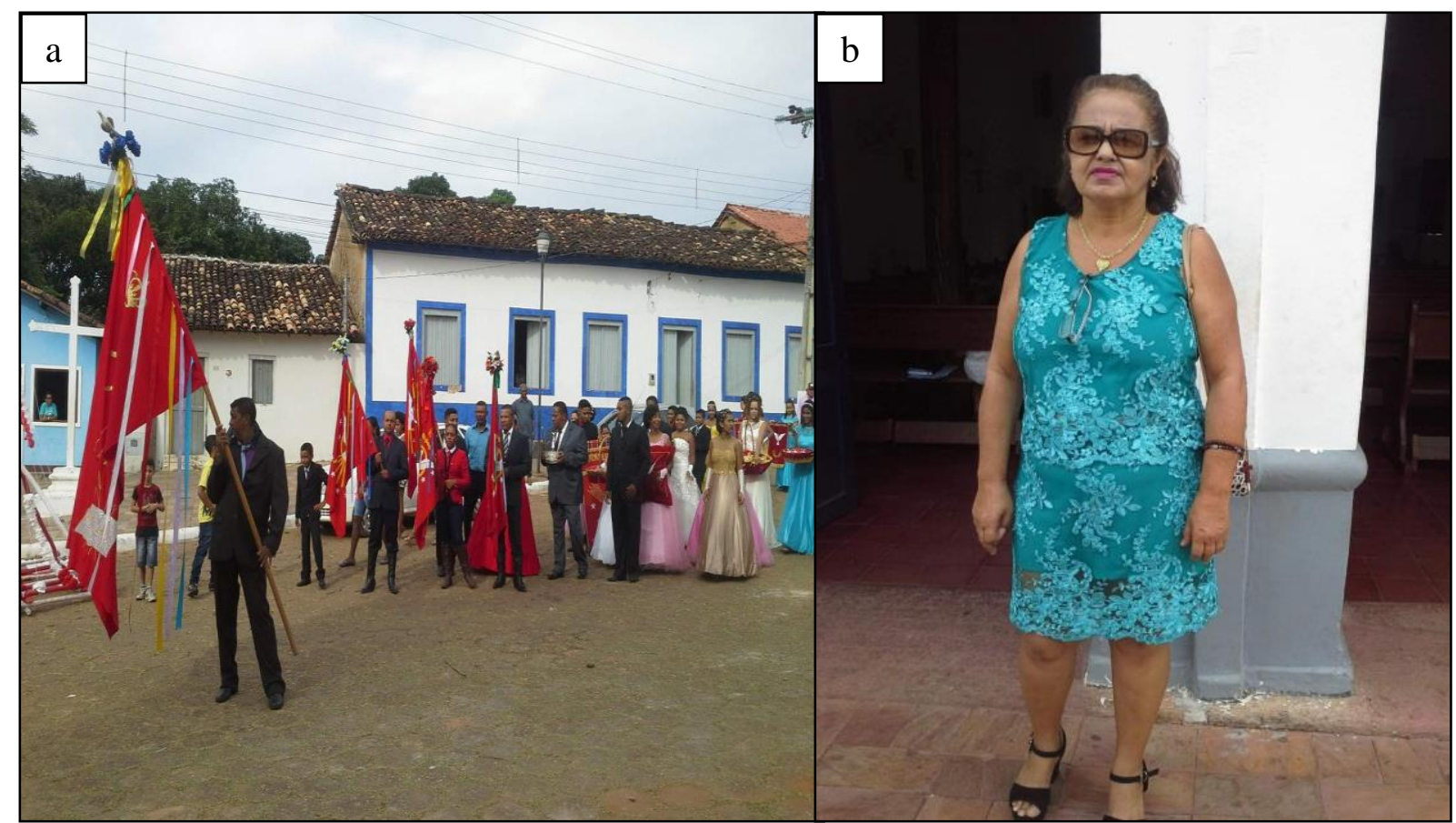

a) Festa de Nossa Senhora da Natividade; b) Mulher nativitana usando joia em filigrana. Fonte: Wátila Bonfim, 2018.

No Estado do Tocantins, as manifestações culturais se relacionam às festas religiosas, a de Nossa Senhora da Natividade é uma tradição de quase três séculos (IPHAN, 2007). O que motivou a eleição desta padroeira como a santa padroeira do Estado do Tocantins, acontecendo todos os anos o novenário com barracas e leilões ao final das missas.

\begin{abstract}
A festa da Padroeira acontece em Natividade, entre os dias 30-08 a 08-09, mantendo data fixa ao longo dos anos. A festividade tem como seu ponto forte as novenas que ocorrem durante todo este período até o dia sete. Logo pela manhã, todos os dias são realizadas missas. No dia sete há a missa pela manhã que é a missa pela Pátria, em seguida tem batizados às nove horas. $\mathrm{O}$ dia 8 de setembro é o momento mais significativo, é o dia em que se comemora o nascimento de Maria (IPHAN, 2007, p. 3)
\end{abstract}

\title{
CARACTERIZAÇÃO DAS JOIAS E MEMÓRIA
}

Ressalta Santos (2006), que a partir da segunda metade do século XVIII, a mineração de ouro em Natividade começou a entrar em declínio, apesar de pequenas prospecções terem continuado, utilizando-se a mão de obra escravizada. Mesmo com essa diminuição da faina extrativa a sociedade nativitana não adormeceu completamente, pois algumas de suas igrejas, como Nossa Senhora do Rosário dos Pretos e São Benedito, foram erguidas já no final do século XVIII. E segundo a tradição 
oral da cidade, o próprio ouvidor do Norte, Joaquim Teotônio Segurado, mudou-se para Natividade a fim de dirigir administrativamente aquela região da Capitania.

Após a decadência aurífera nas minas goianas, conforme Santos (2006, p. 7) "[...] a agricultura e a pecuária minimizam o isolamento econômico da região, os canaviais e as rezes mesmo proibidos eram mantidos paralelamente à mineração, passaram a ser estimulados pelo governo [...]".

Atualmente, a ourivesaria trabalhada nas oficinas pelos artesãos filigraneiros de Natividade, representa a simbologia imaterial da cidade, assim como as festas de Nossa Senhora da Natividade, do Divino Espírito Santo e da Romaria do Senhor do Bonfim. Algo comum entre estas práticas é a sua secularidade.

Por enquanto há poucos trabalhos acadêmicos sobre a ourivesaria nativitana, e da prática do ofício de artesãos filigraneiros e da filigrana no Brasil. Entretanto, de acordo com relatos e moradores, é uma herança portuguesa, que em Natividade se fez realidade devido a abundância de ouro na região, um certo isolamento cultural, e do hábito dos mestres-ourives e/ou filigraneiros repassarem a técnica a seus aprendizes (SANTOS, 2006).

Cada modelo de peça possui um sentido especial. Em Natividade, as joias que expressam símbolos cristãos são usados tanto por devotos, quanto por não devotos. Os lugares que remetem à prática e experiência religiosa são muito importantes ainda hoje em Natividade: a Igreja de Nossa Senhora da Natividade, a Igreja de São Benedito, as ruínas de Nossa Senhora do Rosário dos Pretos, templos do período colonial e que são das mais importantes referências culturais da comunidade. Também o Calendário é marcado pelas festas religiosas, a Festa do Divino é um momento especial para usar os crucifixos e as "pombinhas do Divino", e também outras joias (IPHAN, 2007, p. 69).

Para os ourives e ex-ourives, algumas peças se relacionam mais estreitamente com a memória, como o Coração Português, Divino (filigranado), e a Peixa (Figura 4).

Figura 4. Coração Português/ Divino/ Peixa. 


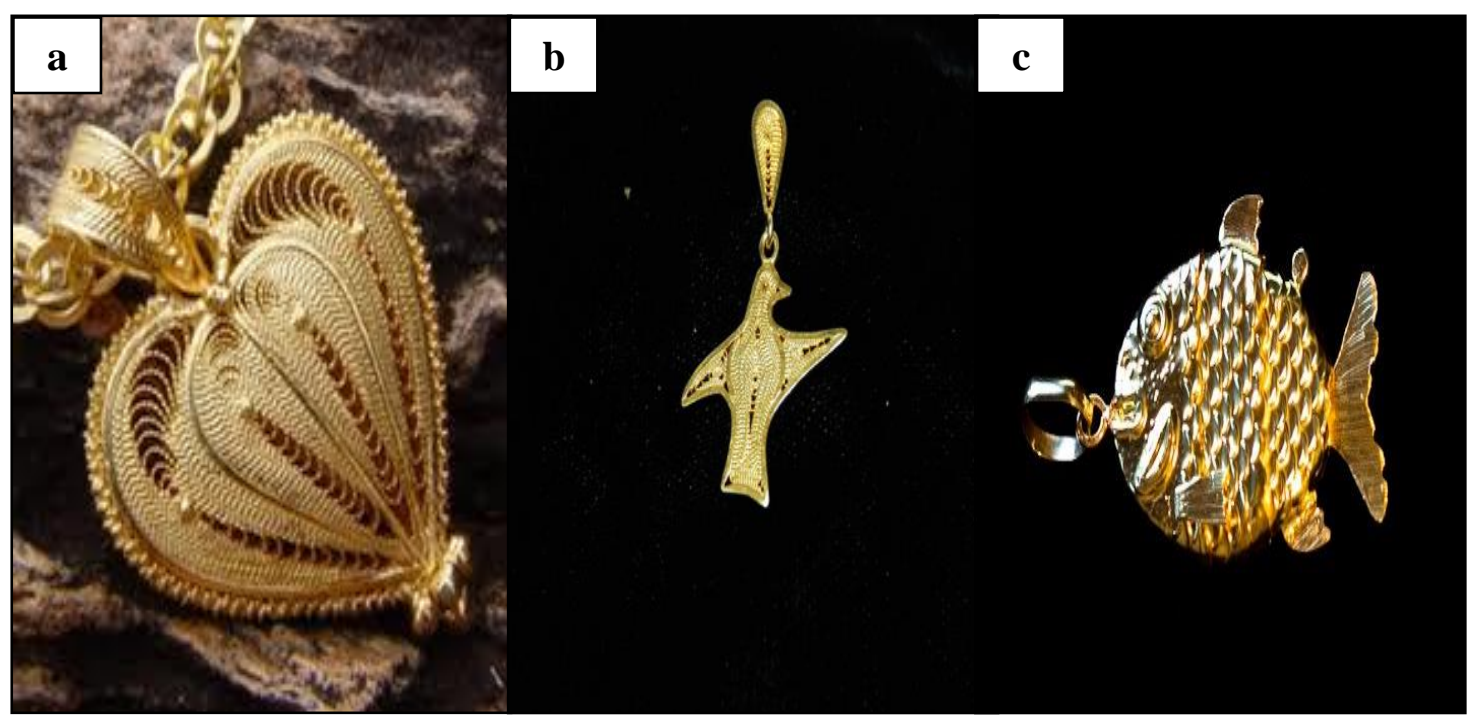

a) Coração Português; b) Divino; c) Peixa. Fonte: ASCCUNA, 2018, adaptada pelo autor, 2019.

O conceito de lugar, enfoca Marandola Júnior (2014), possui a materialidade que lhe dá o ambiente utilizado pelo sujeito em sua própria construção. Surge a partir da combinação, pelo sujeito, de lógicas naturais e humanas diversas, o lugar adquire o caráter de objetividade de seus componentes. Assim, “[...] o lugar repousa sobre a ideia de um sujeito ativo que deve, sem cessar, tecer as ligações complexas que lhe dão sua identidade, ao mesmo tempo em que definem suas relações com seu ambiente" (MARANDOLA JÚNIOR, 2014, p. 110).

A natureza social da identidade, do sentimento de pertencimento ao lugar ou das formas de apropriação do espaço que ela suscita, liga-se aos lugares habitados, marcados pela presença, criados pela história fragmentária feita de resíduos e de detritos, pela acumulação de tempos, marcados, remarcados, nomeados, natureza transformada pela prática social, produto de uma capacidade criadora, acumulação cultural que se inscreve num espaço e tempo (CARLOS, 1996, p. 30).

O lugar de acordo Tuan (2013) pode ser definido de diversas maneiras. Dentre elas, esta: lugar é qualquer objeto estável que capta nossa atenção. Quando olhamos uma cena panorâmica, nossos olhos se detêm em pontos de interesse. Quando paramos é tempo suficiente para criarmos uma imagem de lugar que, em nossa opinião, momentaneamente parece maior. A parada, Tuan (2013, p. 199) “'[...] pode ser de tão curta duração e de interesse tão fugaz, que podemos não estar completamente conscientes de ter detido nossa atenção em nenhum objeto em particular, acreditamos que

EO3 - Era muito difícil naquela época pra puxar a filigrana, dava trabalho...Levava o dia todo, tudo manual. Eu que introduzi a cravação em Natividade. 
É provável, que tanto em Natividade, como foi em Portugal, que as peças em filigrana fossem associadas no passado às classes de menor poder aquisitivo. Para Santos (2006), tal motivo se explica pelo fato de as joias filigranadas serem mais leves que as peças maciças. Assim as joias em filigrana eram de mais fácil acesso que as demais, chamadas maciças. Ainda hoje, uma das opções dos compradores são tanto por razões estéticas como também econômicas.

Com uma quantidade razoável de ouro ou prata é possível fazer uma joia filigranada por exemplo, o que permite que cidadãos com posses pouco expressivas também adquiram algum exemplar, seja em ouro ou prata. Podemos classificar como joias com uso da filigrana em Natividade: Coração Nativo, Coração Português, brinco Flor de Maracujá etc.; e como joias maciças ou feitas com placas trabalhadas de metal que até podem receber a filigrana ou não: crucifixo, Anel Escravo, a Peixa, colar de Lantejoula etc.

Dentre as muitas peças fabricadas artesanalmente, algumas são mais lembradas por sua ancestralidade e tradição, como a Peixa, os Corações Português e Nativo, crucifixos, Anel Escravo ou Anelão, a Pomba do Divino; outras são mais novas, como o colar Cartier e brinco Capim Dourado (SANTOS, 2006).

As peças artesanais fabricadas nas oficinas são espécies de ícones da identidade de Natividade. De acordo com (WAL, 2015), estão entre as principais peças da ourivesaria nativitana: pingente Coração Nativo em ouro, brinco Flor de Maracujá com 6 pétalas em ouro, Colar de Lantejoula em ouro, pingente Peixa em ouro, Colar Elo Português em prata, Anel Escravo em ouro, pingente Divino em prata.

EO1 - O brinco Flor de Maracujá, acho que tem mais de 200 anos...O brinco Flor de Maracujá já existia antes, era mais rústico, a maior parte das peças já existia...O Divino....Nós só foi aperfeiçoando.

A "Peixa" é um dos grandes símbolos da ourivesaria tradicional nativitana. De acordo com a tradição oral da cidade. Como explica Santos (2006) as moças nativitanas que saíam para morar fora eram identificadas pelo uso da "Peixa" seja em ouro ou prata. Outra representação dada pelos moradores é o sentido religioso, pois o peixe é também considerado um símbolo da cristandade.

EO3 - A Peixa tinha muito naquela época, porque é uma tradição...tem muita relação com a família.

M7 - A joia que meu pai me deu eu guardo com muito carinho. Uma lembrança, é uma Peixa, quando eu uso, lembro dele. 


\title{
CONSIDERAÇÕES FINAIS
}

As joias que são produzidas, de acordo com inventários consultados, há mais de um século nas oficinas de Natividade marcam sua estreita relação com o lugar e compõe o patrimônio local.

\begin{abstract}
O lugar é a base da reprodução da vida e pode ser analisado pela tríade habitante-identidade-lugar. A cidade, por exemplo, produz e revela-se no plano da vida e do indivíduo. Este plano é aquele do local. As relações que os indivíduos mantêm com os espaços habitados se exprimem todos os dias nos modos de uso, nas condições mais banais, no secundário, no acidental. É o espaço possível de ser sentido, pensado, apropriado e vivido através do corpo (CARLOS, 1996, p. 20).
\end{abstract}

Ensina Carlos (1996), que o homem percebe o mundo através de seu corpo, de seus sentidos. É assim que ele vai construindo e se apropriando do espaço e do mundo. O lugar, desse modo, é uma fração do espaço apropriável para a vida, seguindo nessa órbita os passos de seus moradores. Já a produção espacial se realizaria no plano do cotidiano, aparecendo nas formas de apropriação, utilização e ocupação de um determinado lugar, num momento específico, revelando-se pelo uso como uso da divisão social e técnica de trabalho (CARLOS, 1996).

Todas essas festas de origem cristã, enfatiza Ferreira (2005), trazem à tona uma identidade cultural que resiste ao tempo e às influências da globalização. Possuem uma força que é herança cultural de milênios.

E é através dos adereços que essa herança se torna mais evidente, pois carrega consigo um conjunto de símbolos e códigos. Seu significado está no subconsciente dos indivíduos. E representa sua visão do mundo através das peças que seguem padrões e regras antigas.

\section{REFERÊNCIAS BIBLIOGRÁFICAS}

CARLOS, Ana Fani Alessandri. O lugar no/do mundo. São Paulo: FFLCH, 1996.

FERREIRA, Maria Nazareth (Org). Identidade cultural e turismo emancipador. São Paulo: Celacc/ ECA/ USP, 2005.

GUARNIERI, Thais; RIBEIRO, Mariana. Filigrana: história e técnica. São Paulo: LCTE Editora, 2012. 
IPHAN. INRC de Natividade: estudos para o registro da ourivesaria em filigrana de Natividade, Tocantins como patrimônio cultural imaterial brasileiro. Brasília, DF, 2007.

KARASCH, Mary. Os quilombos do ouro na capitania de Goiás. In: XAVIER, Giovana (Org.). Mulheres negras no Brasil escravista e do pós-emancipação. São Paulo: Selo Negro, 2012.

MARANDOLA JUNIOR, Eduardo. Sobre ontologias. In: MARANDOLA JUNIOR, Eduardo; HOLZER, Werther; OLIVEIRA, Lívia de. (Orgs.). Qual o espaço do lugar?: geografia, epistemologia, fenomenologia. São Paulo: Perspectiva, 2014.

MARQUES, Iolanda Vanessa Lopes Ribeiros Alves. Estudo para aplicações de filigrana portuguesa em acessórios de moda. 2014. 157 f. Tese (Doutorado em Design) - Universidade de Aveiro - UA, Aveiro, 2014. Disponível em: <https://ria.ua.pt/bitstream/10773/13187/1/Tese.pdf>. Acesso em: 23 jun. 2017.

MENDES, Estevane de Paula Pontes; SILVA, Juniele Martins. Abordagem qualiltativa e Geografia: pesquisa documental, entrevista e observação. In: MARAFON, José Glauco; RAMIRES, Júlio Cesar de Lima; RIBEIRO, Miguel Angelo; PESSÔA, Vera Lúcia Salazar (Orgs.). Pesquisa qualitativa na geografia: reflexões teóricoconceituais e aplicadas. Rio de Janeiro: EdUERJ, 2013.

PALACÍN, Luís. O patrimônio histórico de Goiás. Brasília: SPHAN/Pró-memória, 1987.

PEREIRA, Mafalda Pinheiro. Memórias de artesãos filigraneiros de Gondomar Um patrimônio a musealizar?. 2008. 242 f. Dissertação (Mestrado em Museologia) Universidade do Porto - U. Porto, Faculdade de Letras da Universidade do Porto, 2008. Disponível em: <https://repositorio-aberto.up.pt/handle/10216/8540?mode=full $>$. Acesso em: 02 jul. 2017.

POHL, Johann Emanuel. Viagem no interior do Brasil. Belo Horizonte: Editora Itatiaia; São Paulo, Editora da Universidade de São Paulo, 1976.

SANTOS, Cláudia Borges dos. Joias de Natividade: confluências e conflitos. 2006. 21 f. Monografia de Conclusão de Curso (Graduação em Comunicação Social) Universidade Federal do Tocantins - UFT, Palmas, 2006. Disponível em: <download.uft.edu.br/?...Regulamento\%20para\%20Trabalho\%20de\%20Conclusão\% 20. ..> Acesso em: 13 set. 2017.

TUAN, Yi-Fu. Espaço e lugar. Londrina: Eduel, 2013.

VAZ, Maria Diva Araújo Coelho. Natividade. Brasília: MEC-Pró-memória, 1985.

WAL, Mestre; ARAÚJO, Simone Câmelo. Manual 7 joias artesanais de Natividade Tocantins por mestre. Natividade, TO: 10 - Empresa de Comunicação, 2015. 